\title{
Cultura política y radicalización de la Nueva Izquierda latinoamericana en los sesenta globales
}

Reseña: Aldo Marchesi, Latin America's Radical Left: Rebellion and Cold War in the Global 1960s, Cambridge University Press, 2018, 257 pp.

\section{Rosa María Mantilla Suárez *}

$Q^{n}$ n el complejo mapa ideológico de la izquierda, la pregunta sobre el cambio social y sus condiciones se renueva a la luz de distintos momentos. La generación política de la llamada "Nueva Izquierda" de los años sesenta y setenta en el Cono Sur abocó por la organización política violenta transnacional como el único modo para el cambio social, a contracorriente pero también con la mirada puesta en su propia tradición política. El libro del historiador uruguayo, Aldo Marchesi, Latin America's Radical Left: Rebellion and Cold War in the Global 1960s aborda la emergencia, el desarrollo y el declive de esta red de organizaciones de jóvenes militantes desde la historia política y cultural, bajo una perspectiva transnacional y crítica a los discursos elaborados a partir de los años ochenta desde la académica y en la esfera pública. Concretamente, en el libro se examina la radicalización política de esta generación, concepto utilizado por el autor para entender el proceso por el cual los militantes propusieron nuevas prácticas y formas de acción colectiva en respuesta a la crisis de las formas tradicionales de participación.

En lugar de plantear una respuesta unilateral, Marchesi encuentra tres capas del mismo proceso que dio a estas organizaciones de izquierda

\footnotetext{
* Socióloga, editora de vocación y estudiante de historia en Columbia University. Correo: roses9293@gmail.com
} 
las características que las distinguieron de otras de América Latina y del mundo: 1) el marco global de los años sesenta en el que se inscribió y ocupó un rol importante la red regional de organizaciones armadas de Uruguay, Chile, Argentina, Bolivia y Brasil; 2) la violencia y la estrategia armada en América Latina como una cultura política transnacional, y 3) el autoritarismo moderno instaurado en el Cono Sur que generó un proceso regional de exilio. Es por ello que los aportes de la investigación no se hallan solo en la rica descripción de los caminos de la radicalización, sino también en el plano teórico y metodológico de la investigación, pues desde la perspectiva histórica debate con la literatura política y sociológica que ha intentado explicar esas tres capas del proceso.

Primero, Marchesi se inserta en los estudios sobre los sesenta globales y las especificidades de las organizaciones armadas del Cono Sur. Una mirada detallada a los debates al interior y entre las organizaciones demuestra que, aunque se sumergieron en el movimiento político global del disenso, fueron capaces de resignificar los lenguajes, producir nuevos repertorios y convertirse en actores clave que, a su vez, impactaron en los sectores radicales de Estados Unidos y Europa. Asimismo, en el análisis de las prácticas y de los lenguajes, Marchesi juega con la relación entre ruptura y tradición, pues da cuenta de la crítica generacional a la izquierda tradicional pero también de los puntos de convergencia.

En segundo lugar, el enfoque histórico de la investigación permitió descentrar a la idea de una naturaleza antiliberal y antidemocrática de las organizaciones como explicación sobre la violencia política de la época. Marchesi ubica en el contexto de la transición a la democracia los discursos que estigmatizaron la violencia de estos agentes y los trabajos académicos del liberalismo democrático que explicaron desde la ideología todo el proceso de radicalización. En este sentido, realiza un trabajo sobre 
la memoria colectiva y pública. Con base en el principio metodológico de historiar las categorías políticas, recrea las formas en las que la generación de militantes construyó gradualmente las definiciones e interpretaciones, los recursos simbólicos y las prácticas.

Tercero, el autor recupera dos corrientes del pensamiento social; por un lado, el estructuralismo de los años sesenta y setenta que señaló el surgimiento de estas organizaciones como resultado inevitable de la crisis del modelo industrialista y, por el otro, los estudios del lenguaje y las ideas de los años noventa que describieron la cultura interna de las organizaciones y las explicaron como parte de un movimiento cultural global. A la luz de dichos marcos interpretativos, no se explican los caminos de la radicalización política. La propuesta de Marchesi es conectar las transformaciones políticas y económicas con los procesos ideológicos y culturales; en otras palabras, busca entender las dinámicas por las cuales los militantes de la Nueva Izquierda recogieron el lenguaje político global y construyeron sus propias categorías políticas desde las condiciones socioeconómicas particulares de la región.

Desde una perspectiva histórica, Marchesi utiliza las categorías sociológicas de proceso político, estructura de oportunidades políticas, repertorios de acción y subjetividad política para leer el abanico de fuentes orales y escritas que van desde las entrevistas y testimonios, las publicaciones y documentos internos de las organizaciones, hasta los documentos oficiales. Las fuentes también recogen una estrategia política del momento: las publicaciones periódicas y culturales en las que se debatió y difundió la cultura política de la izquierda radical.

En cuarto lugar, el autor se ubica en la nueva tendencia de la disciplina histórica por descentrar los espacios nacionales. En este sentido, el concepto de "cultura política transnacional" permite entender el activismo desde las 
acciones o prácticas, las ideas e interpretaciones sobre el proceso político regional, la subjetividad política y la construcción de una identidad de comunidad que se juntó física y simbólicamente en el exilio. A su vez, es una forma de superar las dicotomías entre estructura e ideología y entre procesos locales y globales.

La complejidad de trazar las redes regionales, dibujar las trayectorias de los militantes y determinar la transformación de los lenguajes políticos se resolvió en el análisis y la presentación de la investigación en cinco capítulos centrados en una ciudad en distintos momentos desde 1962 hasta 1989 y las nuevas democracias.

El momento de renovación de los repertorios de contienda de la Nueva Izquierda del Cono Sur, cuyo eje de conspiración fue Montevideo entre 1962 y 1968 se aborda en el primer capítulo. Los militantes de estas incipientes organizaciones de Argentina, Brasil, Chile y Uruguay se vieron en la necesidad de adaptar las ideas de la Revolución Cubana a su contexto socioeconómico y político y a sus propias prácticas y discursos radicales que se pueden rastrear hasta mediados de 1950. En efecto, los años sesenta encontraron a estos países con sociedades urbanizadas, un amplio desarrollo de las clases medias y regímenes democráticos, pero también con la crisis del modelo de desarrollo que trajo consigo la emergencia de movimientos sociales disruptivos y descontentos con las izquierdas de sus países y la fuerte reacción estatal. En Chile, por ejemplo, Clotario Blest reunió a unionistas, jóvenes, miembros insatisfechos con los partidos socialista y comunista y grupos trotskistas y anarquistas para formar el MIR en 1965.

Estos nuevos activistas, aunque públicamente apoyando la Revolución Cubana, buscaron fórmulas alternativas. Distintos factores contribuyeron a una discusión abierta sobre las formas de la guerra armada en el sur: el incremento de publicaciones periódicas y culturales que dieron a conocer la 
experiencia de la Revolución, la llegada de los textos canónicos, estratégicos y testimoniales, la política exterior cubana que, aunque buscaba exportar la experiencia revolucionaria, excluyó a los países del sur de su objetivo, el fracaso de la primera ola de guerrillas rurales, como la EGP en Argentina, y los exilios regionales en Uruguay.

El país, aunque rodeado de dictaduras e inmerso en la retórica de la Guerra Fría, no había prohibido los partidos de izquierda. En este espacio se asentó una amplia comunidad de paraguayos, argentinos, bolivianos, brasileños exiliados tras el golpe de 1954 y refugiados de la guerra civil española, quienes incorporaron en la agenda regional la discusión sobre los métodos y estrategias de la lucha política. Este encuentro de experiencias transnacionales dio como resultado el surgimiento de los Tupamaros (MNL-T) en 1966, quienes construyeron a la guerrilla urbana como un modelo alternativo al cubano.

Marchesi encuentra que, en este primer momento, la definición ideológica fue relativamente vaga, se hablaba de la revolución desde el plano moral y se hacía un llamado a la radicalización. Sin embargo, la dimensión simbólica de sus prácticas fue estratégica para denunciar el aumento del autoritarismo en la región y planear una política alternativa que desafíe a la política electoral de la izquierda tradicional y a la estrategia del foquismo, lo cual reavivó las expectativas de quienes creían en la violencia revolucionaria como camino para el cambio social al sur del continente. La experiencia del MNL-T inspiró a otros movimientos de la región, incluyendo al PRT-ERP argentino, a guerrillas incipientes en Brasil y al mismo MIR chileno.

El segundo capítulo se centra en la construcción y profundización de la identidad política de la Nueva Izquierda alrededor de la solidaridad continental revolucionaria a partir de dos eventos de 1967, la Conferencia de la Organización Latinoamericana de Solidaridad en la Havana y el fracaso 
de la campaña de Guevara para establecer un foco rural en Bolivia. Ambos eventos permitieron construir una cercanía subjetiva en el mapa de América Latina.

En la Primera Conferencia Tricontinental de La Habana de 1966 convergieron Allende y Castro, dos voces públicamente distintas pero que coincidían en un mismo movimiento histórico hacia el socialismo y el antiimperialismo. A la luz de los debates, Marchesi encuentra que se adoptó el lenguaje de la revolución y el socialismo y se llamó a coordinar las acciones en la región. Este discurso sobre la estrategia continental de la revolución fue una mutación del lenguaje político importante, la cual se concretó en julio de 1967 con la Conferencia de la Organización Latinoamericana de Solidaridad (OLAS).

La Conferencia mostró la división de la izquierda en relación con las estrategias políticas para acceder al poder y combatir el imperialismo en el marco de la Guerra Fría: por un lado, la de los partidos comunistas cercanos a la Unión Soviética, quienes defendían una visión moderada y basada en la participación en las elecciones, y, por el otro, la posición cubana, que argumentaba que la única vía para promover la solidaridad era desplegar la lucha armada continental, postura que prevaleció al final de la Conferencia. Por primera vez se reunieron organizaciones de izquierda para responder la pregunta de cómo establecer efectivamente lazos solidarios, aunque, paradójicamente, los más cercanos a la postura cubana no participaron oficialmente, entre ellos el MIR y el PTR. Ante ello, la Organización de los Estados Americanos (OEA) lanzó una campaña que también fue utilizada por Cuba para reforzar su centralidad en la revolución.

En el marco del malestar social in crescendo, las acciones represivas de gobiernos democráticamente electos y la polarización entre la OEA y OLAS en la región, las incipientes organizaciones políticas encontraron nuevos 
elementos para leer la lucha política de la región. El autor demuestra cómo el sentimiento de pertenencia a un movimiento colectivo que trascendía los bordes nacionales favoreció a la construcción de una identidad política. De cierta manera, demuestra cómo hay aspectos que escapan a la estructura formal racional de la política y que radican en las creencias, valores y emociones. Este mapa de organizaciones de la Nueva Izquierda se construyó no solo desde un proyecto discursivo, sino también desde las imágenes, expectativas y la construcción de estrategias políticas alrededor de ellas. Si bien la revolución continental no prosperó y sufrió golpes importantes, como la derrota del foco en Bolivia y la muerte de Guevara, la difusión de esta subjetividad política animó a las organizaciones a continuar la lucha armada.

El tercer capítulo retrata el centro intelectual y militante en que se convirtió Santiago de Chile entre 1970 y 1973, desde la victoria electoral del partido de la Unidad Popular, que abrió el país a los militantes de la región con base en una política pluralista y latinoamericanista, hasta el golpe de Estado y el despliegue de una represión militar que conmovió a la izquierda en general. Fue en Santiago donde se fortaleció la red transnacional en la que confluyeron militantes de distintas experiencias, quienes experimentaron el fenómeno regional del autoritarismo. Además, se asumió la solidaridad en acciones políticas concretas cuando militantes del MIR, del PRT-EPR, ELN y los Tupamaros crearon la Junta de Coordinación Revolucionaria (JCR).

En efecto, en este momento las organizaciones se homogeneizaron en un sentido ideológico y también desde una interpretación histórica y estructural sobre la sociedad. Las organizaciones de la Nueva Izquierda que se habían formado de un amplio rango de posturas ideológicas realmente se definieron como organizaciones marxistas leninistas no soviéticas en este período. Este primer elemento se explica porque Santiago era un centro de encuentro 
de intelectuales exiliados, quienes ofrecieron un marco para entender el marxismo leninismo pero distanciados de la ortodoxia comunista. El segundo aspecto de la homogeneización tiene que ver con una interpretación común sobre el proceso histórico de América Latina, muy cercana a la teoría de la dependencia, que justificó académica y políticamente las opciones más radicales. Estas certezas ideológicas en las organizaciones acrecentaron el sentido de pertenencia a una comunidad más amplia y, en definitiva, fortalecieron la cultura política.

El capítulo IV aborda la ronda "decisiva" de la revolución en el Cono Sur, así concebida tanto por los grupos de izquierda como las fuerzas armadas. Se centra en las acciones concretas de la JCR desde Buenos Aires entre 1973 y 1976, cuando implementó políticas de alcance internacional. El liderazgo del PRT-ERP en la JCR se dio en un momento en que el fracaso del proyecto de Allende fortaleció la posición radical y en el que Argentina se convirtió en un lugar de resistencia para estas organizaciones que veían el avance del autoritarismo de la región.

El rechazo del PRT-ERP al nuevo régimen peronista y el surgimiento de grupos de extrema derecha que, con el apoyo del gobierno, atacaron a militantes, artistas e intelectuales de izquierda, radicalizaron la estrategia contra el gobierno de Perón. Desde Argentina, los militantes exiliados planearon varios intentos de reingreso, pero fueron eficazmente contenidos por la creciente coordinación de las acciones de los servicios militares de inteligencia de los países del Cono Sur, a través de la OEA y de los Estados Unidos, que, a través de la Operación Cóndor y una serie de acciones previas, apuntaron a una guerra psicológica y política contra cualquier forma de expresión del amplio espectro de la izquierda. La derrota de las operaciones debilitó las fuerzas del PRT-ERP y el golpe militar de 1976 
significó la represión en amplia escala y el fin de la JCR en Argentina, que llevó sus actividades al exterior.

En este capítulo, Marchesi explica el enfrentamiento violento de estas organizaciones en un contexto democrático como el de Perón en Argentina no como una falla en la interpretación del proceso político, sino como el resultado histórico de la radicalización de esa cultura política regional, que se había construido desde los años sesenta. Fue la culminación del proyecto político que los popularizó durante las dictaduras y que los desacreditó durante el período democrático.

Finalmente, el quinto capítulo muestra la transición de la lucha armada a los nuevos movimientos sociales y políticos en el marco de los regímenes democráticos en la década de 1980. Este proceso implicó una mutación paulatina de la cultura política revolucionaria, una evaluación de las nuevas circunstancias y no tanto de un cambio ideológico radical. Aunque cada grupo tomó un camino particular, la tensión compartida fue la de encontrar una manera de reconciliar la tradición de la insurgencia armada con el nuevo clima de renovación. Las posibilidades de integración al nuevo clima democrático dependieron de la estructura de oportunidades y de las políticas de amnistía y retorno del exilio. Así, los países que implementaron amnistías políticas, como Uruguay y Brasil, favorecieron a la integración de los grupos armados en las nuevas democracias.

En el nuevo lenguaje se incorporó la interpretación gramsciana sobre la hegemonía, para la cual el rol de la sociedad civil y de los intelectuales era central en la acción colectiva. Además, se incorporó una nueva sensibilidad alrededor de los derechos humanos, ampliamente difundida por organizaciones internacionales como Amnistía Internacional, las Naciones Unidas e, inclusive, la Organización de los Estados Americanos. Bajo estas 
condiciones, la izquierda se encontró ante un momento de revalorización de los valores democráticos.

Para Marchesi, hay varios factores que permiten evaluar el impacto de esta cultura política más allá del 'fracaso' de la estrategia armada, tal como se interpretó en el período de transición. Las lecturas sobre la lucha revolucionaria armada a partir de la literatura testimonial en los años noventa, la reivindicación de los derechos humanos, la participación de varios exmilitantes en el sistema político de la democracia liberal y la simpatía despertada por ciertos sectores en los últimos gobiernos progresistas han demostrado el impacto regional y actual de dichas organizaciones.

En definitiva, esta investigación da cuenta de la fluidez del período histórico, en el cual el lenguaje global del anticolonialismo y la liberación nacional se reescribió activamente desde el Cono Sur. Logra rastrear las redes de debate, actores y movimientos en un espacio geográfico amplio y se enfoca en los cuadros de clase media de esta época que constituían el núcleo de los movimientos: líderes, jóvenes, estudiantes e intelectuales que debatían las estrategias para concretar la revolución y abogaban por una que incorporara a los sectores de clase baja, ignorados por la izquierda tradicional. El libro abre la pregunta sobre cómo incorporaron a estos sectores en sus espacios heterogéneos de militancia, cómo caló en ellos esta cultura política y de qué manera asumieron la radicalización.

Latin America's Radical Left es un aporte fundamental a la historia política reciente y se inserta en los debates públicos de la memoria. La Nueva Izquierda es parte de la tradición de la política actual y su estructura de sentimientos, valores y expectativas ha sido revalorizada a la luz de recientes gobiernos progresistas inscritos en la lógica política electoral. El texto demuestra que, aunque ha levantado múltiples y ampliamente 
aceptados cuestionamientos desde distintos sectores, inclusive al interior de la misma izquierda, es posible abordar el tema de la violencia política no desde la reivindicación ni desde el estigma, sino desde aplicación del método histórico radical sobre las fuentes. 